\section{BMJ}

Open

Gastroenterology

\title{
Diagnostic accuracy of a pH stick, modified to detect gastric lipase, to confirm the correct placement of nasogastric tubes
}

\author{
Anne M Rowat, ${ }^{1}$ Catriona Graham, ${ }^{2}$ Martin Dennis ${ }^{3}$
}

To cite: Rowat AM, Graham C, Dennis M. Diagnostic accuracy of a pH stick, modified to detect gastric lipase, to confirm the correct placement of nasogastric tubes. BMJ Open Gastro 2018;5:e000218. doi:10.1136/ bmjgast-2018-000218

Received 31 May 2018 Revised 29 June 2018 Accepted 5 July 2018

\section{Check for updates}

(C) Author(s) (or their employer(s)) 2018. Re-use permitted under CC BY-NC. No commercial re-use. See rights and permissions. Published by BMJ.

${ }^{1}$ School of Health and Social Care, Edinburgh Napier University, Edinburgh, UK ${ }^{2}$ Edinburgh Clinical Research Facility, University of Edinburgh, Western General Hospital, Edinburgh, UK

${ }^{3}$ Centre for Clinical Brain Sciences, University of Edinburgh, Edinburgh, UK

Correspondence to Dr Anne M Rowat; a.rowat@napier.ac.uk

\section{ABSTRACT}

Objective The correct placement of a nasogastric feeding tube is usually confirmed by establishing that an aspirate is acidic using a pH stick. However, antacid medication and achlorhydria can cause false negative $\mathrm{pH}$ tests that may delay feeding and increase resource use. The purpose of this study was to evaluate a modified $\mathrm{pH}$ stick designed to detect gastric lipase and therefore reduce false negative tests.

Methods In this prospective observational study, a convenience sample of adult patients who had either gastric and oesophageal samples taken during routine diagnostic gastroscopy $(n=97)$ or bronchial and saliva samples taken during a bronchoscopy $(n=106)$. The samples were tested by blinded observers using the modified and standard pH sticks. The sensitivities and specificities of the two pH sticks in identifying gastric and non-gastric aspirates were compared using the $\mathrm{pH}$ cut-off $\leq 5.5$.

Results The sensitivities of a $\mathrm{pH} \leq 5.5$ to correctly identify gastric samples were $66 \%$ (95\% Cl 56 to 75 ) and $68 \%$ (95\% Cl 57 to 77 ) for the modified and the standard pH, respectively. The specificities were $81 \%$ (95\% Cl 76 to $85)$ and $79 \%$ (95\% Cl 74 to 84$)$. There were no significant differences in the distribution of the discordant results between the paired gastric and non-gastric samples for both the modified and standard $\mathrm{pH}$ sticks at $\mathrm{pH} \leq 5.5$ (both McNemar's tests, $p \geq 0.05$ ).

Conclusions There were no significant differences between the paired modified and standard $\mathrm{pH}$ tests for the gastric samples. Due to the limited accuracy of $\mathrm{pH}$ sticks, further research is required to identify accurate and cost-effective bedside methods to confirm the correct placement of nasogastric tubes.

\section{INTRODUCTION}

The $\mathrm{pH}$ of an aspirate cut-off $\leq 5.5$ is commonly used as the first-line test to confirm that the nasogastric tube (NGT) is correctly positioned in the stomach. ${ }^{1}$ However, it has been reported that false negative $\mathrm{pH}$ tests $(>5.5)$ can occur in patients who secrete less gastric acid, because they receive antacid medications, achlorhydria or buffering by NGT feeds. $^{2-4}$ This can lead to significant delays
Summary box

What is already known about this subject?

- Current guidelines recommend that the first-line test to confirm nasogastric tube (NGT) position is that the $\mathrm{pH}$ of a gastric aspirate is $\leq 5.5$.

- Patients on antacid medications more often have false negative $\mathrm{pH}$ tests $(>5.5)$, which delays feeding and increases the number of chest $\mathrm{X}$-rays (second-line test) to confirm NGT position.

- A previous study found that modified pH sticks, coated with triglyceride to detect human gastric lipase (HGL), were more sensitive to correctly identify NGT position than standard pH sticks.

What are the new findings?

- There were no significant differences between the paired modified and standard $\mathrm{pH}$ tests to differentiate gastric from non-gastric samples taken from fasting patients at $\mathrm{pH} \leq 5.5$.

- The accuracy of $\mathrm{pH}$ remained unchanged, regardless of whether patients were taking antacid medication or not.

How might it impact on clinical practice in the foreseeable future?

- Further refinement of the modified pH stick to accurately detect NGT placement is required, including investigation of the stability of tributyrin coated on different types and makes of sticks and of HGL activity in different patient populations.

to feeding and greater use of chest X-rays to visually confirm the NGT position. ${ }^{5}$ However, misinterpretation of X-rays can lead to significant feeding errors. ${ }^{6}$

A proposed solution to check non-acid gastric aspirates is by using stomach specific enzyme-based diagnostic tests for NGT confirmation. Human gastric lipase (HGL) is mostly secreted from the gastric fundus and is considered to be one of the most acid stable stomach enzymes. ${ }^{7}$ HGL is able to hydrolyse dietary triglycerides that results in the release of butyric acid and alcohol. ${ }^{8}$ Therefore, the 
presence of lipase might be measured through detecting the acid derived from the breakdown of triglycerides. ${ }^{9}$ However, the HGL activity is only stable between $\mathrm{pH}$ 3.0 and 7.0 and is inactive at very acidic $(\mathrm{pH} \leq 2.0)$ and alkaline $\mathrm{pH}$ values $(\mathrm{pH}>8.0) .^{7910}$ Therefore, a combined test that measures both $\mathrm{pH}$ and HGL activity has been hypothesised to be more accurate than the $\mathrm{pH}$ test in isolation. ${ }^{9}$ Modified $\mathrm{pH}$ sticks that detect HGL ( $\mathrm{pH}$ stick supplied by Merck, New Jersey, USA, Ref: 1095840001), which is coated with tributyrin (Ingenza, Roslin, Scotland), were also found to be more sensitive to correctly identify NGT placement than standard $\mathrm{pH}$ sticks $(97 \%$ (95\% CI 85 to 100 ) vs $66 \%$ (95\% CI 48 to 81$)$ ). ${ }^{9}$ However, the sample size was small, including only 36 patients who had aspirates taken from NGTs.

The aim of this study was to compare the diagnostic accuracy of $\mathrm{pH}$ measurements using modified HGL and standard $\mathrm{pH}$ stick results on aspirates obtained during gastroscopy or bronchoscopy at the recommended $\mathrm{pH}$ cut-off of $\leq 5.5$.

\section{METHODS}

This study was carried out as part of a broader study of the accuracy of $\mathrm{pH}$ testing to distinguish gastric aspirate from aspirates from other sites, which has been previously published. ${ }^{11}$

\section{Participants}

In this prospective observational study, a convenience sample of adults ( $\geq 16$ years) who were referred for a first elective diagnostic gastroscopy or bronchoscopy in two UK teaching hospitals between 1 November 2014 and 20 December 2016 were eligible for the study. Eligible patients had data regarding the use of antacid medication or conditions/surgery that might affect the $\mathrm{pH}$ of any aspirate results. Patients were excluded if they were having follow-up procedures, if they lacked mental capacity or the specimens were considered high risk, including known tuberculosis, blood or airborne viruses.

\section{Data collection}

Two aspirates were taken per patient during either gastroscopy (gastric and oesophageal samples) or bronchoscopy (bronchial and saliva samples). Each operator followed site-specific guidance for the collection of gastric, oesophageal and bronchial samples. Patients undergoing bronchoscopy were also asked to spit salvia into labelled containers prior to the procedure. Between 5 and $10 \mathrm{~mL}$ of each type of aspirate were placed into universal containers, which were immediately put on ice to preserve any HGL activity in the gastric fluid for up to 2 hours. ${ }^{10}$ The reference standard was direct confirmation of the type of aspirate confirmed by the operator undertaking the procedure.

The standard CE-marked pH stick was supplied by Enteral UK, North Duffield, UK. A biochemist coated the same $\mathrm{pH}$ test paper with tributyrin (Ingenza, Roslin, Scotland, patent W02011068891A1). It was hypothesised that both sticks would be able to detect hydrochloric acid if present in the stomach $(\mathrm{pH} \leq 5.5)$. However, if there was no hydrochloric acid but HGL was present in the stomach, the HGL would break down the tributyrin on the modified stick to produce butyric acid providing an acidic response. ${ }^{9}$ Both the standard and modified $\mathrm{pH}$ sticks were stored at room temperature in a cool dry place away for direct sunlight, as per the $\mathrm{pH}$ stick manufacturers' instructions, with a minimum expiration date of 3 years. The $\mathrm{pH}$ stick scale ranges from 2.0 to 9.0 with three colour blocks in intervals of $0.5 \mathrm{pH}$ units.

The research nurses tested one of each of the samples with the two visually identical $\mathrm{pH}$ sticks, one standard and one modified to test HGL, within 2 hours of the sample being collected from the patient. The research nurses were blind to the type of stick used and each of the $\mathrm{pH}$ sticks were given a code, so they could not be identified when testing the specimens. The research nurses followed a standard operating procedure to ensure that each specimen was pipetted from the container to cover the two different types of $\mathrm{pH}$ stick (modified and standard) separately to prevent cross-contamination of samples. The colour of the sticks was compared after $60 \mathrm{~s}$ with that on the container. Although visual colour impairment was not formally tested, the research nurses all indicated they had normal colour vision.

\section{Patient involvement}

No patients were involved in the design or implementation of this study.

\section{Analyses}

Demographic categorical data are presented as percentages, the median (IQR), frequencies and 95\% CI. In order to identify the sensitivity, specificity, positive/ negative predictive values (PV) and the positive/negative likelihood ratios (LR) for the standard and modified $\mathrm{pH}$ tests, the cut-off values were aligned to the clinically agreed standards for testing $\mathrm{pH}$, that is, $\leq 5.5$ was classified as acidic sample whereas $>5.5$ was classified as non-acidic sample. All data analyses were performed using Statistical Analysis System Institute, SAS V.9.4, Cary, North Carolina, USA.

The sample size of 100 for each sample was estimated based on the $95 \%$ CIs and the majority of gastric aspirates having a $\mathrm{pH} \leq 5.5$. However, the sample size could vary depending on how many patients have gastric secretions with a $\mathrm{pH}>5.5$, as this was unknown we arbitrarily chose $4 \%$ where $\mathrm{pH}$ might misclassify the samples. We expected no false positives samples when testing saliva or bronchial aspirate, which would give specificity of $100 \%$ (95\% CI 97 to 100$)$. Therefore, we estimated that 200 patients each having two different samples each tested with the two types of $\mathrm{pH}$ sticks, taken during either gastroscopy (gastric and oesophageal samples) or bronchoscopy (bronchial and saliva samples) procedures would be required, providing a total of 800 (400 modified and 400 standard) $\mathrm{pH}$ tests. 
Table 1 The participant characteristics based on whether they had a gastroscopy $(n=97)$ or bronchoscopy ( $=106)$

\begin{tabular}{|c|c|c|c|c|c|c|}
\hline & \multicolumn{2}{|c|}{ Gastroscopy } & \multicolumn{2}{|c|}{ Bronchoscopy } & \multicolumn{2}{|c|}{ Total } \\
\hline & $\mathbf{n}$ & $\%$ & $\mathbf{n}$ & $\%$ & $\mathbf{n}$ & $\%$ \\
\hline Male & 39 & 40 & 56 & 53 & 95 & 47 \\
\hline Female & 58 & 60 & 50 & 47 & 108 & 53 \\
\hline Antacid medication & 42 & 43 & 41 & 39 & 83 & 41 \\
\hline Proton pump inhibitor $\mathrm{H}_{2}$ & 39 & 40 & 40 & 38 & 79 & 39 \\
\hline Antagonist/combination & 3 & 3 & 1 & 1 & 4 & 2 \\
\hline Previous gastric surgery & 1 & 1 & 8 & 8 & 9 & 4 \\
\hline Pernicious anaemia & 2 & 2 & 1 & 1 & 3 & 1 \\
\hline Total $\mathrm{n}$ of participants & 97 & 100 & 106 & 100 & 203 & 100 \\
\hline
\end{tabular}

\section{RESULTS}

A total of 203 patients were included, 97 (48\%) had gastroscopy and $106(52 \%)$ a bronchoscopy. Table 1 shows 95 (47\%) patients were male; 83 (41\%) were taking antacid medication prior to the gastroscopy $(42 / 97,43 \%)$ or bronchoscopy $(41 / 106,39 \%)$; and $3(1 \%)$ had known pernicious anaemia, but these factors did not differ significantly between those who had a gastroscopy or bronchoscopy. Significantly more patients who had bronchoscopy $(8 / 106,8 \%)$ had previous gastric surgery than those who had a gastroscopy $(1 / 97,1 \%)$ (Fisher's Exact test, $\mathrm{p}=0.04)$. There were 390 samples tested with the standard stick and 379 with the modified $\mathrm{pH}$ stick (figure 1).
The median standard and modified $\mathrm{pH}$ were similar for each of the different types of samples at $\mathrm{pH} \leq 5.5$, both in the presence and absence of prior use of antacid medication and/or other confounding factors (table 2). The sensitivity of a $\mathrm{pH} \leq 5.5$ to correctly identify gastric samples was $66 \%$ (95 CI 56 to 75 ) and 68\% (95\% CI 57 to 77) for the modified and standard $\mathrm{pH}$ sticks, respectively. The specificities were $81 \%$ (95 CI 76 to 85 ) and $79 \%(95 \%$ CI 74 to 84 ) for modified and standard pH sticks. There appeared to be no differences in the positive and negative PVs and LRs between the two types of pH stick (table 3).

The gastric $\mathrm{pH}$ was similar in those patients receiving antacid medications (median $\mathrm{pH}=2.0$, IQR 2.0-6.6) compared with those who were not (median $\mathrm{pH}=2.3$, IQR

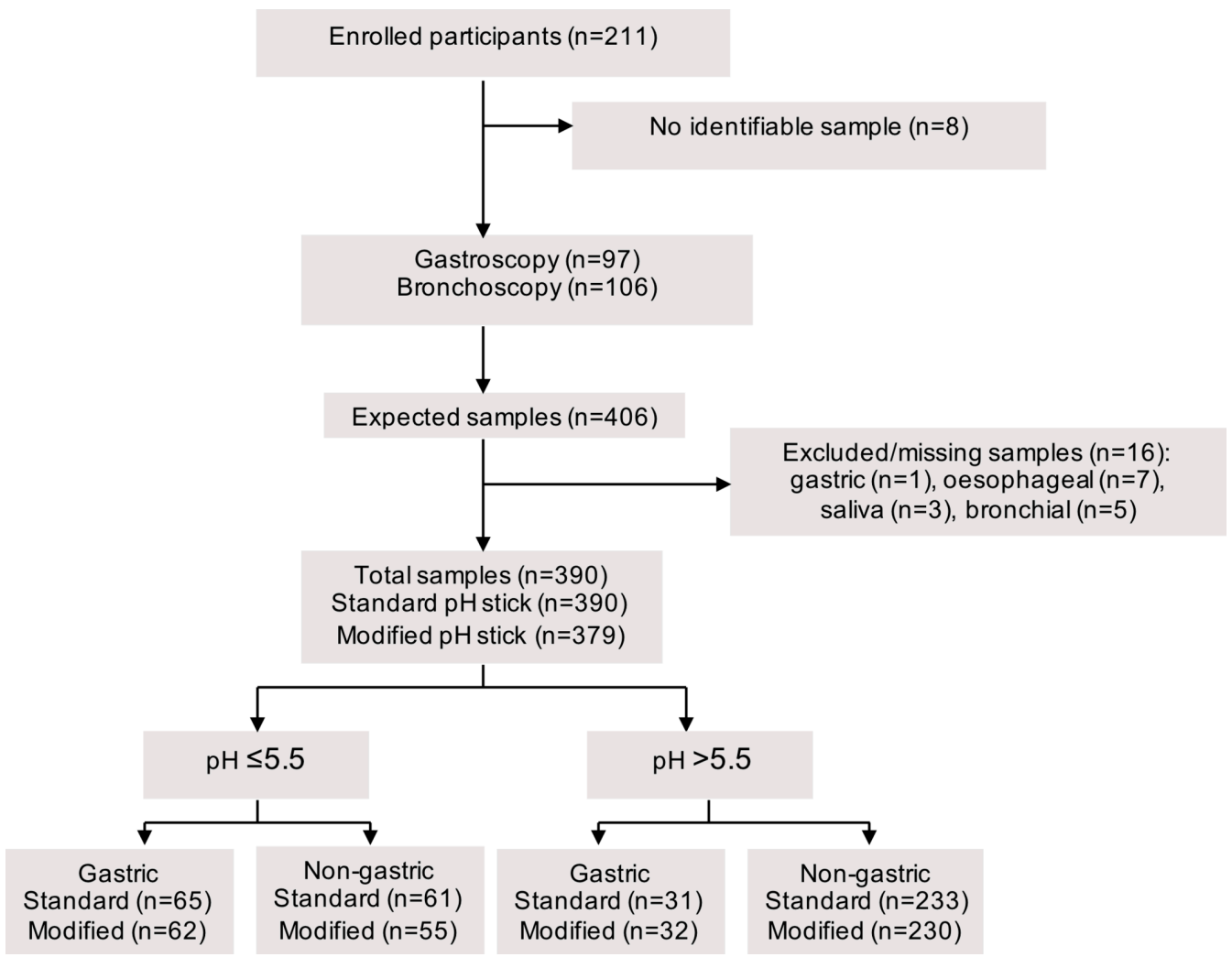

Figure 1 STAndards for the Reporting of Diagnostic accuracy studies (STARD) diagram reporting the flow of participants through the study. 
Table 2 The proportion of samples from different sources with $\mathrm{pH} \leq 5.5$ in the presence and absence of antacid medication

\begin{tabular}{|c|c|c|c|c|c|c|}
\hline \multirow[b]{2}{*}{ Sample } & \multirow[b]{2}{*}{ pH stick } & \multirow{2}{*}{$\begin{array}{l}\text { Median } \\
\text { (IQR) }\end{array}$} & All & $\begin{array}{l}\text { Antacid } \\
\text { medication }\end{array}$ & $\begin{array}{l}\text { No } \\
\text { antacid } \\
\text { medication }\end{array}$ & $\begin{array}{l}\text { All confounding } \\
\text { factors* }\end{array}$ \\
\hline & & & \multicolumn{4}{|c|}{ Number with $\mathrm{pH} \leq 5.5 / \mathrm{n}(\%)$} \\
\hline \multirow[t]{2}{*}{ Gastric } & Standard & $2.5(2.0-6.5)$ & $65 / 96(68)$ & $30 / 42(71)$ & $35 / 54(65)$ & $32 / 44(73)$ \\
\hline & Modified & $2.5(2.0-6.5)$ & $62 / 94(66)$ & $28 / 42(67)$ & $34 / 52(65)$ & $30 / 44(68)$ \\
\hline \multirow[t]{2}{*}{ Oesophageal } & Standard & $5.0(2.0-6.5)$ & $59 / 90(66)$ & $26 / 41(63)$ & $33 / 49(67)$ & $26 / 42(62)$ \\
\hline & Modified & $5.5(2.5-6.5)$ & $53 / 89(60)$ & $22 / 40(55)$ & $31 / 49(63)$ & $22 / 41(54)$ \\
\hline \multirow[t]{2}{*}{ Saliva } & Standard & $7.0(7.0-7.5)$ & 2/101 (2) & $2 / 40(5)$ & $0 / 61(0)$ & $2 / 43(5)$ \\
\hline & Modified & $7.0(7.0-7.5)$ & 2/97 (2) & 1/37 (3) & $1 / 60(2)$ & $1 / 41(2)$ \\
\hline \multirow[t]{2}{*}{ Bronchial } & Standard & $7.0(6.5-7.5)$ & 0/103 (0) & $0 / 41(0)$ & $0 / 62(0)$ & $0 / 45(0)$ \\
\hline & Modified & $7.0(7.0-7.5)$ & 0/99 (0) & 0/41 (0) & $0 / 58(0)$ & $0 / 44(0)$ \\
\hline
\end{tabular}

${ }^{*}$ Confounding factors included antacid medication, pernicious anaemia and/or gastric surgery.

2.0-6.5), regardless of the type of $\mathrm{pH}$ stick. In patients on antacids, the sensitivity of the $\mathrm{pH}$ of gastric samples $(\mathrm{pH} \leq 5.5)$ was $67 \%$ (95\% CI 51 to 80 ) for the modified and $71 \%$ (95\% CI 55 to 84) for the standard pH stick (table 3 ). The sensitivity of gastric samples remained similar when patients with pernicious anaemia $(n=3)$ or had previous gastric surgery $(n=9)$ were included in the analyses: modified stick $=68 \%$ (95\% CI 52 to 81 ) and standard stick $=73 \%$ (95\% CI 57 to 85$)$.

Overall, there were no significant differences in the distribution of the discordant results between the paired gastric (McNemar's test $=0.50, \mathrm{p}=0.5$ ) and non-gastric (McNemar's test=2.13, $\mathrm{p}=0.1$ ) samples for both modified and standard sticks at $\mathrm{pH} \leq 5.5$.

\section{DISCUSSION}

In this study, the modified and standard $\mathrm{pH}$ sticks' sensitivity was low in terms of correctly identifying gastric aspirate, regardless of whether patients were on antacids or had other confounding factors. It has been previously reported that standard $\mathrm{pH}$ testing can have sensitivity ranging between $66 \%-90 \%$ and the differences between results may depend on the type and make of $\mathrm{pH}$ indicator stick. $^{3911-13}$ It was surprising that the modified $\mathrm{pH}$ stick did not demonstrate higher sensitivities similar to those reported by the previous study, particularly in patients with a $\mathrm{pH}>5.5 .^{9}$ We found that a third of the gastric samples had a $\mathrm{pH}>5.5$ suggesting a high prevalence of

Table 3 The diagnostic accuracy of the modified and standard pH stick tests for all gastric samples compared with nongastric samples tested at the $\mathrm{pH} \leq 5.5$, including the absence or presence antacid medication

\begin{tabular}{|c|c|c|c|c|c|}
\hline \multirow[b]{2}{*}{ Diagnostic test } & pH stick & All & $\begin{array}{l}\text { Antacid } \\
\text { medication }\end{array}$ & $\begin{array}{l}\text { No antacid } \\
\text { medication }\end{array}$ & $\begin{array}{l}\text { All confounding } \\
\text { factors* }\end{array}$ \\
\hline & \multicolumn{5}{|c|}{ Gastric $\mathrm{pH} \leq 5.5$ versus all other samples $(95 \% \mathrm{Cl})$} \\
\hline \multirow[t]{2}{*}{ Sensitivity \% } & Standard & 68 (57 to 77$)$ & 71 (55 to 84$)$ & 65 (51 to 77$)$ & 73 (57 to 85$)$ \\
\hline & Modified & 66 (56 to 75$)$ & 67 (51 to 80$)$ & 65 (51 to 78$)$ & 68 (52 to 81$)$ \\
\hline \multirow[t]{2}{*}{ Specificity \% } & Standard & 79 (74 to 84$)$ & 77 (69 to 84$)$ & 84 (74 to 86$)$ & 79 (70 to 85$)$ \\
\hline & Modified & 81 (76 to 85$)$ & 81 (72 to 87$)$ & 81 (70 to 87$)$ & $82(74$ to 88$)$ \\
\hline \multirow[t]{2}{*}{ PPV \% } & Standard & 52 (45 to 58$)$ & 52 (42 to 61$)$ & 53 (44 to 62$)$ & 53 (44 to 62$)$ \\
\hline & Modified & 53 (46 to 59$)$ & 55 (44 to 65$)$ & 57 (46 to 67) & 57 (46 to 67) \\
\hline \multirow[t]{2}{*}{ NPV \% } & Standard & 88 (85 to 91) & 89 (83 to 93) & 90 (84 to 93) & 90 (84 to 93) \\
\hline & Modified & 88 (84 to 90) & 87 (81 to 91) & 88 (83 to 92) & 88 (83 to 92) \\
\hline \multirow[t]{2}{*}{ PLR } & Standard & 3.3 (2.5 to 4.2 ) & 3.1 (2.1 to 4.5 ) & 4.0 (2.7 to 5.9$)$ & 3.4 (2.3 to 4.9$)$ \\
\hline & Modified & 3.4 (2.6 to 4.5$)$ & 3.4 (2.2 to 5.2$)$ & 3.4 (2.5 to 4.2 ) & 4.0 (2.4 to 5.7$)$ \\
\hline \multirow[t]{2}{*}{ NLR } & Standard & 0.4 (0.3 to 0.5$)$ & 0.4 (0.2 to 0.6$)$ & 0.4 (0.3 to 0.6$)$ & 0.4 (0.2 to 0.6$)$ \\
\hline & Modified & 0.4 (0.3 to 0.6$)$ & 0.4 (0.3 to 0.6$)$ & 0.4 (0.3 to 0.6$)$ & 0.4 (0.3 to 0.6$)$ \\
\hline \multirow{2}{*}{$\begin{array}{l}\text { Overall } \\
\text { agreement \% }\end{array}$} & Standard & 76 (72 to 81$)$ & 76 (68 to 82) & 77 (71 to 82) & 77 (70 to 83) \\
\hline & Modified & 77 (73 to 81) & 77 (70 to 83) & 77 (71 to 83) & 78 (71 to 84$)$ \\
\hline
\end{tabular}

${ }^{*}$ Confounding factors included antacid medication, pernicious anaemia and/or gastric surgery.

NLR, negative likelihood ratio; NPV, negative predictive value; PLR, positive likelihood ratio; PPV, positive predictive value. 
hypo/achlorhydria, which is likely to be more common in patients undergoing scope investigations. ${ }^{14}$ It was also predicted that patients taking antacid medication would have higher $\mathrm{pH}$ values than those not receiving antacid medications. ${ }^{2}$ However, in the current study, the accuracy of $\mathrm{pH}$ remained unchanged, regardless of whether patients were taking antacid medication or not. This may be a result of patients being required to fast for up to 4 hours and/or having stopped their antacid medication prior to the procedure, which can increase gastric acid rebound hypersecretion. ${ }^{1516}$

A strength of the current study was the large number of aspirates that were obtained from patients undergoing routine gastroscopy and bronchoscopy. NGT placement cannot be controlled and it would be unethical for patients to have unnecessary chest X-rays. ${ }^{17}$ Furthermore, aspirates cannot be obtained directly from NGTs in up to $46 \%$ of patients. ${ }^{5}$ Although $\mathrm{pH}$ appears to be a cost effective first-line approach to confirm NGT, ${ }^{18}$ studies have shown that the accuracy of $\mathrm{pH}$ sticks remains mixed due to testers' ability to obtain aspirate and visually differentiate the colorimetric results. ${ }^{511} 19$ Previous studies have reported that misreading $\mathrm{pH}$ sticks can be influenced by a number of factors, including testers who have colour vision deficiency, time factors and poor lighting conditions. ${ }^{5} 19$ However, there is a lack of evidence that the use of more expensive $\mathrm{pH}$ meters improves the accuracy to confirm correct NGT placement. ${ }^{3}$ Therefore, redesigning $\mathrm{pH}$ sticks to potentially reduce errors caused by visual inspection should be further investigated. ${ }^{511}$

It is unclear why this large study did not confirm the encouraging results of a similar smaller study. ${ }^{9}$ One explanation might be that different types of $\mathrm{pH}$ sticks were used, although both were prepared by the same laboratory. Studies comparing the different makes and types of $\mathrm{pH}$ stick have been found to either overestimate or underestimate $\mathrm{pH}$ in known buffer solutions. ${ }^{19} 20$ Although pH sticks with multiple colour blocks used in this study are considered to be more accurate than single colour blocks when testing the $\mathrm{pH}$ of buffer solutions, ${ }^{20}$ it was important to determine their performance with different aspirates taken from patients. Second, lipases may also originate from the tongue and the pharynx (lingual lipase); however, studies have found that gastric lipase is the predominant preduodenal enzyme in humans, with only trace amounts of lingual lipase activity detected from the small number of lingual serous glands compared with the larger stomach area. ${ }^{21} 22$ These results were recently corroborated in a study that found no detectable lipase activity from saliva samples (unpublished data) and found that it was not present in lung aspirates. ${ }^{9}$ Third, in this study, the patients had been fasting prior to their procedure, which will reduce the production of gastrin that stimulates both HGL and hydrochloric acid secretion in the stomach. ${ }^{23}$ In the fed state, the conditions are more likely to be favourable for HGL, particularly at elevated $\mathrm{pH}$ levels between $\mathrm{pH}$ 3.0 and $7.0 .^{24}$ If this was indeed the case, HGL may be reduced or not present in the stomach and the modified $\mathrm{pH}$ stick would be unable to correct false negative results. Fourth, there may have been variability between methods used to obtain the samples during the procedure. It is not possible to confirm whether the gastroscopic procedure could inadvertently result in alkaline duodenal fluid to be sampled or mixed the gastric secretions, particularly when the patients are in the supine position. ${ }^{25} 26$ However, there is conflicting evidence whether contamination of gastric contents with bile salts, increases or decreases HGL activity. ${ }^{27}$ Finally, several conditions in humans, including pancreatitis, gastritis, cystic fibrosis and alcoholism, have significantly lower HGL activity when compared with healthy subjects. ${ }^{27}$ In this study, the specimens were deidentified as the aim was to compare the accuracy of both $\mathrm{pH}$ sticks on the different types of aspirate, therefore it was not possible to follow-up patients to confirm diagnosis postprocedure. Furthermore, the population undergoing scope procedures may not be generalisable to those requiring nasogastric feeding. Indeed, the NGT position requires to be checked prior to and after feeding and/or giving medications that will result in variable HGL activity.

\section{Implications for practice and conclusion}

Overall, the sensitivities of the modified and standard $\mathrm{pH}$ tests were low, but both were able to rule out all of the bronchial samples ( $100 \%$ specificity) at the $\mathrm{pH}$ cut-off $\leq 5.5$. The implications for practice based on the findings from this study suggest further refinement of the modified $\mathrm{pH}$ stick is required, including investigation of the stability of HGL at very low and high $\mathrm{pH}$ values; the optimal shelf-life and storage of the tributyrin coated on different types and makes of $\mathrm{pH}$ sticks and the HGL activity in different patient populations, including fasting and feeding status and conditions that are associated with lipase insufficiency. Due to the limited accuracy of current colorimetric $\mathrm{pH}$ sticks, further research is urgently needed to determine more accurate methods that would reduce NGT misplacement and delays in feeding and would be safe, cost-effective, easy to use and improve patient outcomes.

Acknowledgements Data were collected by the research nurses from the Edinburgh Clinical Research Facility, University of Edinburgh. We are grateful to the gastroenterologists and respiratory physicians who helped us by collecting samples during the procedure they carried out. We also wish to thank Ingenza Ltd for providing the modified $\mathrm{pH}$ stick.

Contributors All authors approved the final version of the manuscript. Study concept and design: MD, CG and AMR. Statistical analysis: CG. Acquisition, analysis and interpretation of data and drafting of the manuscript: AMR, CG and MD.

Funding Funded by internal funding from the Centre for Clinical Brain Sciences, University of Edinburgh.

Competing interests None declared.

Patient consent Not required.

Ethics approval Written informed consent was obtained from all respondents. This study received prior approval from the Lothian NHS research ethics committee (REC: 13/SS0184; R\&D: 20130299).

Provenance and peer review Not commissioned; externally peer reviewed. 
Data sharing statement The deidentified dataset will be made available on request to the lead author

Open access This is an open access article distributed in accordance with the Creative Commons Attribution Non Commercial (CC BY-NC 4.0) license, which permits others to distribute, remix, adapt, build upon this work non-commercially, and license their derivative works on different terms, provided the original work is properly cited, appropriate credit is given, any changes made indicated, and the use is non-commercial. See: http://creativecommons.org/licenses/by-nc/4.0/.

\section{REFERENCES}

1. Lamont T, Beaumont $\mathrm{C}$, Fayaz $\mathrm{A}$, et al. Checking placement of nasogastric feeding tubes in adults (interpretation of $x$ ray images): summary of a safety report from the National Patient Safety Agency. BMJ 2011;342:d2586.

2. Gilbertson HR, Rogers EJ, Ukoumunne OC. Determination of a practical $\mathrm{pH}$ cutoff level for reliable confirmation of nasogastric tube placement. JPEN J Parenter Enteral Nutr 2011;35:540-4.

3. Hanna GB, Priest $\mathrm{O}, \mathrm{Ni} \mathrm{M}$, et al. Improving the safety of nasogastric feeding insertion: a report for the NHD Patient Safety Research Portfolio. 2010. http://www.birmingham.ac.uk/Documents/collegemds/haps/projects/cfhep/psrp/finalreports/PS048Improvingth esafetyofnasogastricfeedingtubeinsertionREVISEDHannaetal.pdf (accessed 17 Jan 2018).

4. Fordtran JS, Walsh JH. Gastric acid secretion rate and buffer content of the stomach after eating. Results in normal subjects and in patients with duodenal ulcer. J Clin Invest 1973;52:645-57.

5. Borsci S, Buckle P, Huddy J, et al. Usability study of $\mathrm{pH}$ strips for nasogastric tube placement. PLoS One 2017;12:e0189013.

6 Lee S, Mason E. Competence in confirming correct placement of nasogastric feeding tubes amongst FY1 doctors. BMJ Qual Improv Rep 2013;2:u201014.w1198.

7. Abrams CK, Hamosh M, Lee TC, et al. Gastric lipase: localization in the human stomach. Gastroenterology 1988;95:1460-4.

8. Sams L, Paume J, Giallo J, et al. Relevant $\mathrm{pH}$ and lipase for in vitro models of gastric digestion. Food Funct 2016;7:30-45.

9. Anderson O, Carr R, Harbinson M, et al. Development and validation of a lipase nasogastric tube position test. BMJ Open Gastroenterol 2016;3:e000064.

10. Ville $\mathrm{E}$, Carrière $\mathrm{F}$, Renou $\mathrm{C}$, et al. Physiological study of $\mathrm{pH}$ stability and sensitivity to pepsin of human gastric lipase. Digestion 2002;65:73-81.
11. Rowat AM, Graham C, Dennis M. Study to determine the likely accuracy of $\mathrm{pH}$ testing to confirm nasogastric tube placement. BMJ Open Gastroenterol 2018;5:e000211.

12. Fernandez RS, Chau JP, Thompson DR, et al. Accuracy of biochemical markers for predicting nasogastric tube placement in adults-a systematic review of diagnostic studies. Int J Nurs Stud 2010;47:1037-46.

13. Boeykens K, Steeman E, Duysburgh I. Reliability of $\mathrm{pH}$ measurement and the auscultatory method to confirm the position of a nasogastric tube. Int J Nurs Stud 2014;51:1427-33.

14. Hatta W, lijima K, Koike T, et al. Endoscopic findings for predicting gastric acid secretion status. Dig Endosc 2015;27:582-9.

15. Mohammed R, Holden RJ, Hearns JB, et al. Effects of eight weeks continuous treatment with oral ranitidine and cimetidine on gastric acid secretion, pepsin secretion, and fasting serum gastrin. Gut 1983;24:61-6.

16. Lødrup $A B$, Reimer $C$, Bytzer $P$. Systematic review: symptoms of rebound acid hypersecretion following proton pump inhibitor treatment. Scand J Gastroenterol 2013;48:515-22.

17. Mordiffi SZ, Goh ML, Phua J, et al. Confirming nasogastric tube placement: Is the colorimeter as sensitive and specific as X-ray? A diagnostic accuracy study. Int J Nurs Stud 2016;61:248-57.

18. McFarland A. A cost utility analysis of the clinical algorithm for nasogastric tube placement confirmation in adult hospital patients. $J$ Adv Nurs 2017;73:201-16.

19. Taylor SJ, Clemente R. Confirmation of nasogastric tube position by pH testing. J Hum Nutr Diet 2005;18:371-5.

20. Metheny NA, Gunn EM, Rubbelke CS, et al. Effect of pH teststrip characteristics on accuracy of readings. Crit Care Nurse 2017;37:50-8.

21. Moreau H, Laugier R, Gargouri Y, et al. Human preduodenal lipase is entirely of gastric fundic origin. Gastroenterology 1988;95:1221-6.

22. Gargouri Y, Pieroni G, Lowe PA, et al. Human gastric lipase. the effect of amphiphiles. Eur J Biochem 1986;156:305-10.

23. Olsen O, Wøjdemann M, Berner B, et al. Secretin and gastric lipase secretion. Digestion 1998;59:655-9.

24. Pedersen PB, Vilmann P, Bar-Shalom D, et al. Characterization of fasted human gastric fluid for relevant rheological parameters and gastric lipase activities. Eur J Pharm Biopharm 2013;85:958-65.

25. Stein HJ, Smyrk TC, DeMeester TR, et al. Clinical value of endoscopy and histology in the diagnosis of duodenogastric reflux disease. Surgery 1992;112:796-803.

26. Szarszewski A, Korzon M, Kamiñska B, et al. Duodenogastric reflux: clinical and therapeutic aspects. Arch Dis Child 1999;81:16-20.

27. Tomasik PJ, Wędrychowicz A, Rogatko I, et al. Gastric lipase secretion in children with gastritis. Nutrients 2013;5:2924-32. 